\title{
Resposta terapêutica a diferentes doses de tiamina no tratamento da polioencefalomácia por excesso de carboidratos em caprinos jovens
}

Anna Maria Zimmermann, Flávio Hilgemberg de Carvalho, Felipe Cestari Krasinski,Aline de Marco Viott, Geane Maciel Pagliosa

Universidade Federal do Paraná (UFPR), Palotina, PR, Brasil

*Autor correspondente

e-mail: annamz.vet@gmail.com

\section{Resumo}

A poliencefalomalácea (PEM), enfermidade que acomete ruminantes, é caracterizada por uma necrose cerebrocortical induzida pela deficiência de tiamina. Esta vitamina interfere no metabolismo da glicose no sistema nervoso central, alterando a função dos sistemas enzimáticos intracelulares dependentes de pirofosfato de tiamina, que é uma coenzima necessária no ciclo de Krebs, vital para a produção de energia celular cerebral. Foram atendidos no Hospital Veterinário da Universidade Federal do Paraná - Setor Palotina, em intervalos de 20 dias, seis caprinos da raça Boer, com idade entre 2 e 4 meses e peso 12,6 \pm 3,9 $\mathrm{Kg}$, todos provenientes da mesma propriedade localizada no oeste do Paraná. Os pacientes apresentavam diferentes estágios de evolução clínica da doença e histórico, com início do quadro clínico de inapetência seguida de anorexia, afastamento do grupo, evoluindo para incoordenação motora, cegueira, ataxia e decúbito lateral em 48 horas. Em dois animais também houve opistótono em 72 horas. 0 diagnóstico foi realizado através do histórico, sinais clínicos, resposta ao tratamento com tiamina e, posteriormente, também pelos achados histopatológicos. A etiologia da doença em todos os casos foi a suplementação excessiva de carboidratos na dieta, onde era oferecido aos animais 350 g por dia, sendo que, na faixa etária que os animais se encontravam, a quantidade de matéria seca diária recomendada não deve exceder $2 \%$ do peso corporal. Dos seis animais atendidos, um foi a óbito na admissão e outros três em até 72 horas após o tratamento com $5 \mathrm{mg} / \mathrm{Kg}$ de tiamina a cada doze horas, correspondendo à menor dose terapêutica recomendada pela literatura. Em todos estes animais foi realizada necropsia e avaliação histopatológica, confirmando a suspeita de PEM. Nos dois últimos animais atendidos foi utilizada a dose de $30 \mathrm{mg} / \mathrm{Kg}$ de tiamina para o tratamento, o que resultou na remissão de todos os sinais clínicos em até 72 horas, sendo que estes animais apresentavam cegueira, déficit auditivo, incoordenação motora e opistótono. Considerando os casos atendidos, é possível concluir que o excesso de carboidratos na dieta é um fator desencadeante para a ocorrência da polioencefalomalácea em caprinos jovens e que a dose mínima terapêutica de tiamina recomendada pela literatura de $5 \mathrm{mg} / \mathrm{Kg}$ não é eficaz para a resolução dos sinais clínicos. 